\title{
Mechanism and Kinetics of Precipitation and Dissolution of GP Zone and Metastable Phase in Al-3wt\% Cu Alloy
}

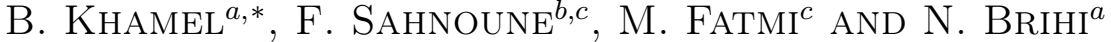 \\ ${ }^{a}$ Department of Physics, Mohammed Saddik Benyahia University, Jijel 18000, Algeria \\ ${ }^{b}$ Physics and Chemistry of Materials Lab, Department of Physics, University Mohamed Boudiaf of M'sila, \\ 28000, M'sila, Algeria \\ ${ }^{c}$ Research Unit on Emerging Materials (RUEM), Ferhat Abbas of Setif 01, Setif 19000, Algeria

\begin{abstract}
Thermal analysis techniques remain important tools amongst the large variety of methods used for analysis of the precipitation and dissolution of the Guinier-Preston zone and metastable phase $\theta^{\prime}$ in $\mathrm{Al}-3 \mathrm{wt} \% \mathrm{Cu}$. In the present study, the kinetics of precipitation and dissolution of the Guinier-Preston zone and metastable phase $\theta^{\prime}$ in $\mathrm{Al}-3 \mathrm{wt} \% \mathrm{Cu}$ was investigated using differential scanning calorimetry carried out between room temperature and $430{ }^{\circ} \mathrm{C}$ at heating rates of 20,25 , and $30^{\circ} \mathrm{C} \mathrm{min}^{-1}$. The activation energies evaluated through isothermal differential scanning calorimetry treatment using the Johnson-Mehl-Avrami theory were 25, 100, and $80 \mathrm{~kJ} \mathrm{~mol}^{-1}$ for the Guinier-Preston zone precipitation, formation of $\theta^{\prime} / \theta$ and dissolution of $\theta^{\prime}$, respectively. The Avrami constant $n$ obtained by the Ligero method was about 1.5 for the formation of $\theta^{\prime} / \theta$ indicating that bulk nucleation is dominant in $\theta^{\prime} / \theta$ formation controlled by diffusion from a constant number of nuclei.
\end{abstract}

DOI: 10.12693 /APhysPolA.131.133

PACS/topics: 81.30.Mh, 81.70.Pg, 81.30.Bx

\section{Introduction}

The heat-treatable Al alloys, as the utmost important structural materials, which are strengthened by the formation of precipitates, are extensively used in the automotive and aviation industries [1]. $\mathrm{Al}-\mathrm{Cu}$, one of the most important Al-base alloys, is strengthened by precipitation of the metastable precipitates [2]. The precipitation sequence observed on ageing these alloys, supersaturated solid solution (SSSS) $\rightarrow$ Guinier-Preston I zones (GPI zones) $\rightarrow$ (GPII zones) $\rightarrow$ $\theta^{\prime} \rightarrow \theta[2]$. The differential scanning calorimetry (DSC) is a common technique to study the thermodynamics and kinetics of phase changes in materials and is particularly useful to investigate precipitation reactions $[3,4]$. The method is based on the difference in the amount of heat required to increase the temperature of a sample and a reference material, respectively.

In the experiment, sample and reference material are heated linearly in a furnace. The sample in the test crucible can undergo phase transformations, which either release (exothermic) or consume (endothermic) energy in the form of heat (enthalpy under constant pressure). Nucleation and growth of precipitates is an exothermic reaction that releases energy (heat) from the system to the surroundings, whereas the dissolution of precipitates is endothermic and requires energy from the surrounding [5-12]. The expression of energy for GP zones in the $\mathrm{Al}-\mathrm{Cu}$ alloys is established by combining the essential Gibbs energy with the interfacial energy and the strain energy. Based on the equilibrium between GP zones and

*corresponding author; e-mail: khamelbillal@yahoo.com the surrounding matrix, a quantitative analysis on the sizes, concentrations, ageing temperatures and their relationships have been shown by Jing et al. [13]. Investigation of sputter-deposited $\mathrm{Al}-2$ at.\% Cu layers by means of the tomographic atom probe by Choi et al. [14], confirms that the $\mathrm{Al}$ grains show columnar shape in the as-sputtered state, where the matrix is supersaturated with $\mathrm{Cu}$. Upon annealing at temperatures between 150 and $350^{\circ} \mathrm{C}$, a significant decrease in the average $\mathrm{Cu}$ concentration is measured within the grains. Our present contribution contains various calculated kinetic parameters. The measured parameters have been used to model the reaction based upon the kinetics theory of Johnson, Mehl, and Avrami of the precipitation of GP zones in the supersaturated $\mathrm{Al}-3 \mathrm{wt} \% \mathrm{Cu}$ alloy, and the transformed volume fraction of the precipitated product nucleated at grain boundaries with the ageing time under isothermal condition using DSC analysis.

\section{Material and experimental procedure}

The $\mathrm{Al}-\mathrm{Cu}$ alloy prepared for this work contained $96.79 \%$ of $\mathrm{Al}, 3 \%$ of $\mathrm{Cu},(<0.10 \% \mathrm{Si})$ and $(<0.11 \% \mathrm{Fe})$. These alloys have been prepared in our laboratory by fusion in a devise at high vacuum (10-5 Torr) using pure materials. After melting the ingots have undergone plastic deformation by cold rolling before the homogenization treatment in order to accelerate the structure homogenization kinetics. The homogenization temperature and ageing were chosen from the equilibrium diagrams. The ingots were homogenized in vacuum at $430^{\circ} \mathrm{C}$ for $3 \mathrm{~h}$ and quenched in water for obtaining a super saturated solid solution; we have prepared a disc shape of $3 \mathrm{~mm}$ diameter and $1 \mathrm{~mm}$ thickness for DSC analysis. DSC experiments were performed on samples using a SETARAM Labevo thermal analyser. 


\section{Result and discussion}

Figure 1 shows typical DSC curves of $\mathrm{Al}-3 \mathrm{wt} \% \mathrm{Cu}$ alloy from room temperature to $400^{\circ} \mathrm{C}$ at a heating rate of $20^{\circ} \mathrm{C} \mathrm{min}^{-1}$, three peaks were observed. The first exothermic peak (I) is due to the precipitation of GP zone. The second exothermic peak (II) corresponds to the precipitation of $\theta^{\prime} / \theta$ phases and the endothermic peak (III) is due to the dissolution of $\theta^{\prime}$. The peak temperature $T_{p}$ for different heating rates of precipitation of GP zone, formation of $\theta^{\prime} / \theta$ and dissolution of $\theta^{\prime}$ are listed in Table I. It can be clearly seen that the increase of heating rate from 20 to $30^{\circ} \mathrm{C} / \mathrm{min}$ shifts the temperature of the maximum of the peak position, $T_{p}$.

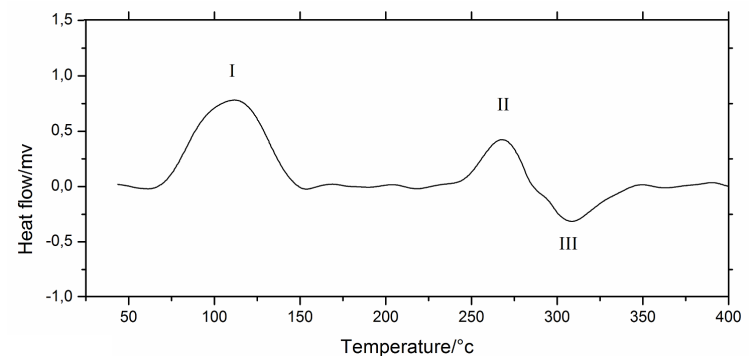

Fig. 1. DSC curves of $\mathrm{Al}-3 \mathrm{wt} \% \mathrm{Cu}$ alloy from room temperature to $400^{\circ} \mathrm{C}$ at a heating rate of $20^{\circ} \mathrm{C} \mathrm{min}-1$.

TABLE I

The peak temperature for different heating rates of precipitation of GP zone, formation of $\theta^{\prime} / \theta$ and dissolution of $\theta^{\prime}$.

\begin{tabular}{c|c|c|c}
\hline \hline The heating rates & \multicolumn{3}{|c}{ Peak temperature $T_{p}\left[{ }^{\circ} \mathrm{C}\right]$} \\
\cline { 2 - 4 } & $\begin{array}{c}\text { precipitation } \\
\text { of GP zone }\end{array}$ & $\begin{array}{c}\text { formation } \\
\text { of } \theta^{\prime} / \theta\end{array}$ & $\begin{array}{c}\text { dissolution } \\
\text { of } \theta^{\prime}\end{array}$ \\
\hline $20^{\circ} \mathrm{C} / \mathrm{min}$ & 107 & 275 & 304 \\
$25^{\circ} \mathrm{C} / \mathrm{min}$ & 119 & 280 & 312 \\
$30^{\circ} \mathrm{C} / \mathrm{min}$ & 207 & 285 & 31
\end{tabular}

The variation of the crystallized fraction and the rate of crystallized fraction with time of the precipitation of GP zone and precipitation of $\theta^{\prime} / \theta$ phases under different heating rates are shown in Fig. 2.

The crystallized fraction $x$ can be determined from the DSC results as [15]:

$$
x=\frac{A_{T}}{A_{0}},
$$

where $A_{T}$ is the area of the peak in the DSC curve at temperature $T$ and $A_{0}$ is the total area of the peak. The rate of crystallized fraction increases with increasing heating rate. The Johnson-Mehl-Avrami theory [15] can be used to evaluate the crystallized fraction under isothermal condition as follows:

$$
x=1-\exp \left(-(k t)^{n}\right),
$$

where $x$ is the volume fraction crystallized after time $t$, $n$ is the Avrami exponent and $k$ is the reaction rate constant, whose temperature dependence is generally expressed by the Arrhenius-type equation
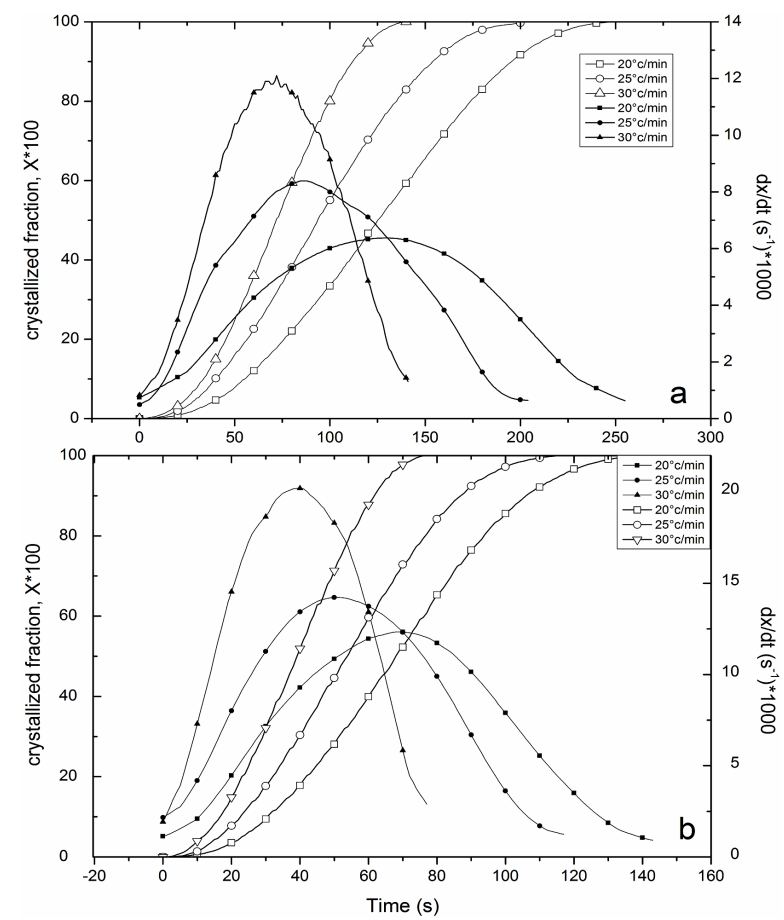

Fig. 2. The variation of the crystallized fraction $x$ and the rate of crystallized fraction with time at different heating rates (a) precipitation of GP zone and (b) formation of $\theta^{\prime} / \theta$ in $\mathrm{Al}-3 \mathrm{wt} \% \mathrm{Cu}$.
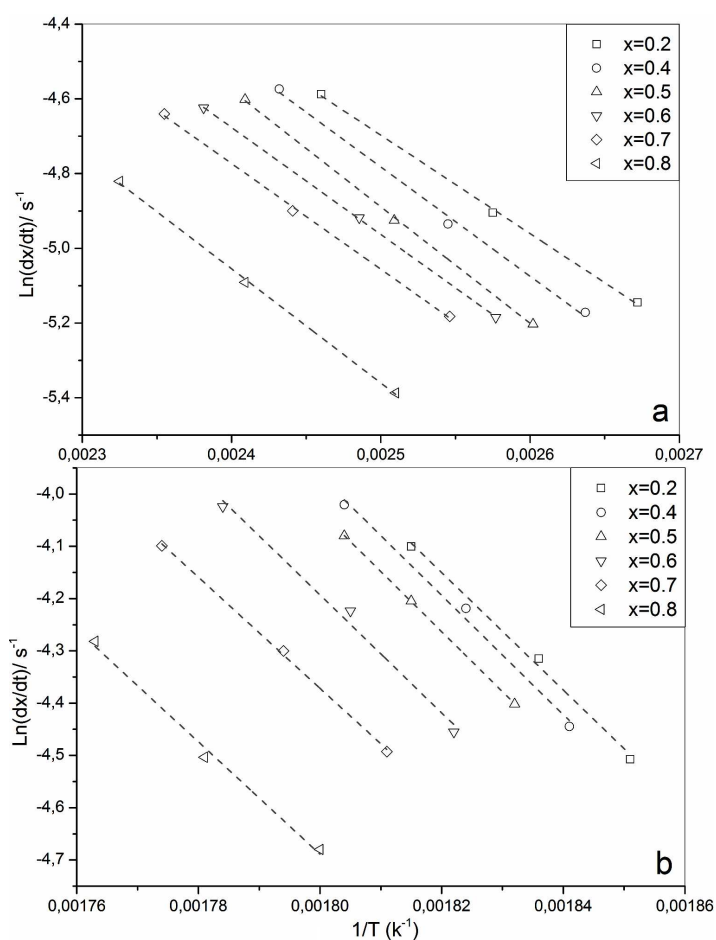

Fig. 3. Plot of $\ln (\mathrm{d} x / \mathrm{d} t)$ versus $1 / T$ at the same value of crystallized fraction $x$ : (a) precipitation of GP zone and (b) formation of $\theta^{\prime} / \theta$ at different heating rates of $\mathrm{Al}-3 \mathrm{wt} \% \mathrm{Cu}$ alloy. 


$$
k=k_{0} \exp \left(-\frac{E}{R T}\right),
$$

where $k_{0}$ is the frequency factor, $E$ is the apparent activation energy, $R$ is the ideal gas constant and $T$ is the isothermal temperature in kelvin. Rearrangement of Eqs. (2) and (3) leads to

$$
\begin{gathered}
\ln \frac{\mathrm{d} x}{\mathrm{~d} t}=\ln \left(K_{0} n\right)+\frac{n-1}{n} \ln (-\ln (1-x)) \\
+\ln (1-x)-\frac{E}{R T}=\ln \left(k_{0} f(x)\right)-\frac{E}{R T} .
\end{gathered}
$$

A mathematical method through non-isothermal techniques was proposed by Ligero and co-workers [15, 16]. The same value of $x$ in every experiment at different heating rates is selected, and $\ln (\mathrm{d} x / \mathrm{d} t)$ is plotted as function of $1 / T$ [15]. The results will be a linear curve in Fig. 3, with a slope equal to the activation energy, $E$.

In the same way the peak (III) can be treated and calculated the crystallized fraction $x$ and the rate of crystallized fraction with time for the dissolution of $\theta^{\prime}$. Then the activation energy $E$ of dissolution of $\theta^{\prime}$ can be calculated. The values of activation energy $E$ were calculated by the average of the slopes of the curves (Eq. (3)) for different crystallized fractions and are listed in Table II. The values of the activation energy were 25, 100, and $80 \mathrm{~kJ} \mathrm{~mol}^{-1}$ for GP zone precipitation (columns A), formation of $\theta^{\prime} / \theta(\mathrm{B})$ and dissolution of $\theta^{\prime}(\mathrm{C})$, respectively.

The Avrami parameter which indicates the crystallization mode, $n$, was determined by the selection of many pairs of $x_{1}$ and $x_{2}$ that satisfied the condition $\ln \left(k_{0} f\left(x_{1}\right)\right)=\ln \left(k_{0} f\left(x_{2}\right)\right)[15,16]$ :

$$
n=\frac{\ln \left(\ln \left(1-x_{2}\right) / \ln \left(1-x_{1}\right)\right)}{\ln \left(\left(1-x_{2}\right) \ln \left(1-x_{2}\right) /\left(1-x_{1}\right) \ln \left(1-x_{1}\right)\right)} .
$$

The values of the Avrami parameter, $n$, of formation of $\theta^{\prime} / \theta$ are listed in Table III. The average Avrami parameter is 1.44. This value is close to 1.5 , which suggests that the process of formation of $\theta^{\prime} / \theta$ is diffusion controlled; this value is with a good agreement to the work of Fatmi et al. in the $\mathrm{Al}-3.7 \mathrm{wt} \% \mathrm{Cu}$ alloy $[17,18]$.

\section{TABLE II}

Values of the activation energy, $E[\mathrm{~kJ} / \mathrm{mol}]$, for different crystallized fraction of $\mathrm{Al}-3 \mathrm{wt} \% \mathrm{Cu}$ alloy

\begin{tabular}{c|c|c|c|c|c|c}
\hline \hline \multirow{2}{*}{$x$} & \multicolumn{2}{|c|}{$\mathrm{A}$} & \multicolumn{2}{c|}{$\mathrm{B}$} & \multicolumn{2}{c}{$\mathrm{C}$} \\
\cline { 2 - 7 } & $E$ & $r$ & $E$ & $r$ & $E$ & $r$ \\
\hline 0.2 & 23.84 & 0.997 & 106 & 0.998 & 83 & 0.998 \\
0.4 & 27.66 & 0.999 & 95.72 & 0.998 & 82 & 0.998 \\
0.5 & 28.61 & 0.997 & 102.96 & 0.999 & 80 & 0.999 \\
0.6 & 21.5 & 0.997 & 96.76 & 0.997 & 77 & 0.999 \\
0.7 & 22.37 & 0.998 & 103.12 & 0.996 & - & - \\
0.8 & 25.4 & 0.999 & 94.6 & 0.998 & - & -
\end{tabular}

\section{TABLE III}

Values of the Avrami parameter $n$ for different heating rates.

\begin{tabular}{c|c|c|c}
\hline \hline$Q[\mathrm{~K} / \mathrm{min}]$ & 20 & 25 & 30 \\
\hline$n$ & 1.49 & 1.40 & 1.42
\end{tabular}

\section{Conclusion}

In the kinetics of precipitation and dissolution of GP zone and metastable phase in $\mathrm{Al}-3 \mathrm{wt} \% \mathrm{Cu}$ was investigated using differential scanning calorimetry. DSC experiments performed under non-isothermal conditions showed exothermic and endothermic peaks. The temperature of precipitation of GP zone, formation of $\theta^{\prime} / \theta$ and dissolution of $\theta^{\prime}$ was found to be around 120, 280, and $312^{\circ} \mathrm{C}$, respectively. The activation energy evaluated through isothermal DSC treatment were 25,100 , and $80 \mathrm{~kJ} \mathrm{~mol}^{-1}$ for GP zone precipitation, formation of $\theta^{\prime} / \theta$, and dissolution of $\theta^{\prime}$, respectively. The $n$ Avrami coefficient that characterizes the transformation mechanism that controls the discontinuous precipitation is 1.5 for the formation of $\theta^{\prime} / \theta$.

\section{References}

[1] E. Hornbogen, E.A. Starke, J. Acta Metal. Mater. 41, 1 (1993).

[2] M.J. Starink, P. Van Mourik, Mater. Sci. Eng. A 156, 183 (1992).

[3] Z. Huang, A. Harris, S.A. Maloy, P. Hosemann, J. Nucl. Mater. 451, 162 (2014).

[4] M. Kreuzeder, M.D. Abad, M.M. Primorac, P. Hosemann, V. Maier, D. Kiener, J. Mater. Sci. 50, 634 (2015)

[5] X. Wang, S. Esmaeili, D.J. Lloyd, Met. Trans. Mater. A 37, 2691 (2006).

[6] A. Gaber, N. Afify, M.S. Mostafa, Gh. Abbady, J. Alloys Comp. 477, 295 (2009).

[7] E.F. Abo Zeid, A. Gaber, M.A. Gaffar, M.S. Mostafa, J. Alloys Comp. 429, 167 (2006).

[8] C. Cayron, P.A. Buffat, Acta Mater. 48, 2639 (2000).

[9] C.D. Marioara, S.J. Andersen, J. Jansen, H.W. Zandbergen, Acta Mater. 51, 789 (2003).

[10] G.C. Weatherly, A. Perovic, D.D. Perovic, N.K. Mukhopadhyay, D.J. Lloyd, Met. Mater. Trans. A 32, 213 (2001).

[11] S.J. Andersen, C.D. Marioara, A. Froseth, R. Vissers, H.W. Zandbergen, Mater. Sci. Eng. A 390, 127 (2005).

[12] S.J. Andersen, C.D. Marioara, R. Vissers, A. Froseth, H.W. Zandbergen, Mater. Sci. Eng. A 444, 157 (2007).

[13] Y. Jing, C. Li, Z. Du, F. Wang, Y. Song, Calphad 32, 164 (2008).

[14] P. Choi, T. Al-Kassab, R. Kirchheim, Scr. Mater. 53, 323 (2005).

[15] M. Romero, J. Martin-Márquez, J.Ma. Rincón, J. Eur. Ceram. Soc. 26, 1647 (2006).

[16] R.A. Ligero, J. Vazques, P. Villares, R. JimenezGaray, J. Mater. Sci. 26, 211 (1991).

[17] M. Fatmi, B. Ghebouli, M.A. Ghebouli, T. Chihi, E. Ouakdi, Z. Heiba, Chin. J. Phys. 51, 1019 (2013).

[18] M. Fatmi, B. Ghebouli, M.A. Ghebouli, T. Chihi, A. Hafiz, Physica B Condens. Matter 406, 2077 (2011). 